\title{
Philosophy of Technology: A Time for Maturation
}

\section{By Philip Brey}

Andrew Feenberg and Alastair Hannay (eds), Technology and the Politics of Knowledge. Bloomington: Indiana

University Press, 1995. Pp. xii +288.

US $\$ 15.95 \mathrm{~PB}, \$ 35 \mathrm{HB}$.

Joseph. C. Pitt (ed.), New Directions in the Philosophy of Technology (Philosophy and Technology vol. 11). Dordrecht: Kluwer, 1995. Pp. ix + 224. US $\$ 99 \mathrm{HB}$.

Roger Fellows (ed.), Philosophy and Technology (Royal Institute of Philosophy Supplement 38).

Cambridge: Cambridge University Press, 1995.

Pp. iv + 208. £13.95 PB.

7 HE philosophy of technology is in a state of growth. In the past two years alone, over a dozen philosophical studies of technology have 1 appeared. ' Occasional references are even made to a 'new wave' in philosophy of technology. Indeed, of the three recent anthologies that will be discussed here, two pretend to present a sampling of 'the new philosophy of technology.' Introducing New Directions in the Philosophy of Technology (henceforth New Directions), Joseph Pitt writes: 'I propose that the papers in this volume represent the advance of the new wave [in philosophy of technology] 
and that as such they offer hope for serious integration of the philosophy of technology into the broader concerns of the philosophical world' (p.viii). Likewise, Feenberg and Hannay present their volume Technology and the Politics of Knowledge (henceforth $T \mathcal{E} P K$ ) as 'a generous sampling of the new philosophy of technology' that 'makes evident the maturity that the field has attained' (p.ix).

Interestingly, these two volumes turn out to be concerned with radically different subject matters, the first being concerned mainly with the internal analysis of the structure and development of technology, the second mainly with the social and political implications of technology. So what does their novelty consist in? An answer to this question requires a brief historical excursion to the 'old' philosophy of technology that these volumes aim to transcend. The traditional corpus in philosophy of technology, if one may call it that, is constituted by the works of a rather diverse company of authors, such as Jacques Ellul, Martin Heidegger, Lewis Mumford, Ivan Illich, Karl Marx, and various members of the Frankfurt School (Marcuse, Adorno, Horkheimer, Habermas). Insofar as they belong to any particular school or approach, these writers tend to be located in either the hermeneutical-phenomenological tradition or in the broad tradition of critical social theory. Not all of them are philosophers by training, and the company includes social scientists, historians, theologians, and engineers.

It is fair to say that the main concern of most authors in this tradition is not so much with the structure and development of technology itself as with the implications of (modern) technology for 'the human condition'. Authors tend to be concerned with what modern technology 'does' to humanity, or what its psychological, cultural, social and political consequences are. Even when the focus is on technology itself, discussions take on a broader significance than one would expect. In ordinary parlance, technology is often identified with the science-based design and control of material artefacts, systems and processes. However, in many works in the tradition of philosophy of technology, a broader definition of technology is employed. Technology is equated with a particular form of rationality or practical intelligence that is thought to permeate the institutions of modern culture. Ellul defines modern technology as any method that is conditioned by the demand for efficiency. He would include managers and politicians, if not ordinary citizens, among those who are constantly implementing technologies. A similariy broad definition is found in Heidegger, who defines technology metaphysically as a 'mode of being-in-the-world', or a particular way of disclosing the world.

A few more features that are typical of much of the tradition in philosophy of technology deserve to be mentioned. First, many works are critical rather than merely expository. This is evident in the ideology critique 
of members of the Frankfurt School, as well as in the condemnations of modern technological society found in the work of Ellul, Mumford, Illich, and many others. Many authors offer warnings or indictments against modern technology or condemn modern technology as part of a bankrupt political system, and some works read as political pamphlets. There is a prevailing pessimism in many authors about the role of modern technology in our lives, a pessimism that culminates in dystopianism in such authors as Ellul, Heidegger and Marcuse. In such authors, technology is seen as an unstoppable, autonomous force, that structures social and political institutions according to its own logic, and erodes the possibilities for self-determination by human agents. It may be noted that the technological pessimism and anti-technological attitudes frequently found in classical philosophy of technology stand in sharp contrast to the pro-science attitudes in the philosophy of science that were until the 1960 s almost universal in that field. Being rooted in different intellectual traditions, these two fields have historically hardly been in contact with each other.

A final characteristic of traditional philosophy of technology lies in its tendency to essentialise technology and to analyse technology from an external, macro-level viewpoint. Such analysis may yield analyses of the general form of technology (defined either broadly or narrowly), of particular types of technology, such as 'traditional' technology, 'modern' technology, or 'democratic' or 'authoritarian' technology (Mumford), or of manifestations of technology in the form of a (socio-)technological system, such as the 'technological universe' (Ellul) or the 'megamachine' (Mumford). Few studies in the tradition look at technology up close and from the inside. There are few studies that focus on particular technologies, or that provide detailed philosophical analyses of artefacts, design processes, engineering practice, technological knowledge, processes of innovation and technological change, and particular episodes in the history of technology.

The tradition described here is, as has been said, rooted in large part in hermeneutical-phenomenological and critical traditions in philosophy. It is a tradition that defines mainstream philosophy of technology. Interestingly, there is hardly a tradition of (general) philosophy of technology in the Anglo-American analytic tradition. The only firmly established research in analytic philosophy that could be counted as belonging to philosophy of technology (but that is often not counted that way) is research in the philosophy of computer science and artificial intelligence. Work in general philosophy of technology in the analytic tradition has been virually nonexistent, with only a handful of monographs and anthologies. ${ }^{2}$ What these works have in common is a focus on technology itself rather than on the consequences of technology, a narrow conception of technology as science-based 
material technology, and detailed attention to the internal structure and dynamics of technology.

The above discussion of various traditions in the philosophy of technology points to its fragmented character. This raises the question whether one can positively identify the philosophy of technology as a genuine academic field. At least until the 1980 s, it would go too far to claim the existence of any such field. Instead, one could point to a heterogeneous body of philosophical work that focused on technology or its consequences. What has changed since then is the establishment of the Society for Philosophy and Technology (established in 1983), an international society that is open to all philosophical traditions, which started to issue newsletters and organise biannual (now annual) international conferences, and has been instrumental in establishing two book series, Research in Philosophy and Technology and Philosophy and Technology.

Still, there is reason for doubt that philosophy of technology now constitutes a coherent academic field. This doubt is reflected in the very name of the Society of Philosophy and Technology, and in the names of the two book series mentioned above. As Paul Durbin, founder of the society and editor of many volumes in both series, explains, he has always tried to avoid the label 'philosophy of technology', instead keeping the society and both series open to all those interested in issues relating to philosophy and technology. 'Philosophy and technology' is then a name for philosophical studies in which there is discussion of technology, a name that eliminates the uncertainty of whether, for example, work in engineering ethics, biomedical ethics, or decision theory applied to technological projects, should be included. As Durbin also points out, there has been a fair amount of resistance by some leading philosophers of technology - he mentions Ellul and his followers in particular - against professionalism and the idea of philosophy of technology as a professional field. ${ }^{3}$

If the desire to keep a broad scope and resistance to professionalisation are two factors explaining the difficulty philosophy of technology has establishing itself as an academic field, another factor may lie in the difficulty in delineating a coherent scope for the field. A coherent scope requires a coherent subject matter for analysis that is clearly delineated from other academic fields. However, as pointed out before, the notion of technology tends to be used in different ways, sometimes referring narrowly to science-based material technology, but often referring to much broader phenomena. Perhaps even more important is the fact that mainstream philosophy does not focus as much on technology as it does on implications of technology. Hence, philosophy of technology is hardly analogous to the philosophy of science, in which the emphasis lies on the analysis of the intrinsic structure and dynamics of science, rather than the social or cultural 
implications of science. As is evident from the preceding, a conception of philosophy of technology analogous to the philosophy of science is only prevalent in 'analytic' philosophy of technology.

Because mainstream philosophy of technology has tended to focus on the social, cultural and psychological implications of technology, its subject matter tends to coincide with other subfields in philosophy such as social and political philosophy, philosophy of culture, and metaphysics. This brings with it the problem of distinguishing the philosophy of technology from these fields. This problem may not be impossible to overcome, as long as one allows for overlap between fields. One may then define the philosophy of technology as a field concerned with the philosophical analysis of technology (defined broadly) as well as with the specific implications of technology for culture, society, and 'the self'. Some studies will then count as studies both in the philosophy of technology and in another area. For example, a philosophical study of the cultural implications of computers could be seen as part of the task of a philosophy of technology, even if it may also be seen as part of a philosophy of culture. Likewise, a philosophical study of the relation between technology and democracy can be seen as an exercise in both philosophy of technology as well as in political philosophy.

\section{T\&PK}

If there are no insurmountable obstacles to establish philosophy of technology as a coherent academic field that may become part of mainstream philosophy, what may such a field look like? TEPK and New Directions both promise to offer us a vision of a mature philosophy of technology. In TEPK, one finds the most recent incarnation of mainstream philosophy of technology. This volume contains essays by many of the major figures in contemporary mainstream philosophy of technology, such as Don Ihde, Albert Borgmann, Langdon Winner and Andrew Feenberg, as well as by philosophically minded scholars in related fields, such as Donna Haraway and Bruno Latour. Like the tradition in philosophy of technology, this work is concerned primarily with the philosophical analysis of the social, political, cultural and psychological implications of technology. Many themes found in the tradition recur here, such as the themes of technology as ideology, the relation between technology and democracy, the alienating character of modern technology, and the technological transformation of the lifeworld.

$T \& P K$ contains sixteen essays found under seven headings, ably introduced by the editors. The philosophical legacy of Heidegger and the Frankfurt School looms large. Three essays, by Feenberg, Vogel and Pippin, focus on the technology-as-ideology thesis of the Frankfurt School, whereas three others, by Dreyfus, Winograd and Rockmore, focus on the 
contributions of Heidegger to the philosophy of technology. Of the remaining ten essays, virually all focus on the social, political and cultural implications of technology. Theme sections include 'Technology and the Moral Order,' 'Media Theories: The Politics of Seeing,' 'Feminist Perspectives: Knowledge and Bodies,' 'Eccentric Positions,' and 'The Human and the Non-Human'. Some of the essays in these sections find their inspiration in the work of classical authors, such as the essay by Tijmes, who considers Hannah Arendt's philosophy of science and technology, and the essay by Dumouchel, which considers Gilbert Simondon's philosophy of technology. Other essays present contemporary analyses that draw from various sources.

So what is new about the work featured in TEPK? First, there are novel themes, such as the relation between technology and the body, and the ontology of technical artefacts. But the claimed novelty of the work presented cannot just be attributed to novel themes. It is also presented as a more mature discussion of classical themes. As the editors point out, "Considerable progress in historical, sociological, and cultural studies of technology has made available a large body of literature on every aspect of the subject and philosophers of technology have not been slow to appreciate it' (p.ix). Indeed, many of the essays show an appreciation of empirical work in technology studies, work that allows for more informed philosophical discussion and a more rigorous testing of claims.

The most significant consequence of this appreciation of empirical work in technology studies may be the embrace of a constructivist perspective as found in the work of a number of authors. The essentialism and technological determinism frequently found in traditional philosophy of technology, incompatible as they are with a constructivist outlook, hence appear to be on the wane. What also appears to be waning is the pessimism and despair found in some work in the tradition. Many authors in TEPK who are discontent with modern technology argue for technological reform or democratisation of technology, instead of despairing or celebrating the blessings of premodern cultures.

A constructivist outlook is evident in Feenberg's essay, in which the Frankfurt School approach to technology is 'updated' in terms of the new constructivist sociology of technology, and in Vogel's essay, in which Habermas and Marcuse are criticised from a constructivist point of view. Longino, taking up constructivist themes, provides a 'post-empiricist' critique of current reproductive technique based on an analysis of the social values in the research context from which they have emerged. A rejection of essentialism and technological determinism is also found in Rockmore, who argues against Heidegger's account of technology in terms of a transpersonal being rather than as a product of human purposes. Rockmore argues that this 
conception of technology leads to anti-humanistic and undemocratic viewpoints in Heidegger's thought.

In emphasising that technologies are the product of human choices and not (just) the logical outcome of science and technological rationality, these essays point to the reform of technology as the answer to any negative role of technologies in our lives. This theme of reform is also voiced in Winner's essay, in which it is argued that the separation between technology and the public sphere must be overcome, and that a new concept of citizenship is needed. It is also found in Winograd's essay, which discusses the positive impact of Heidegger's work on information technologies. Winograd argues that computer scientists have been using Heidegger's work, not to condemn computer technology, but to arrive at more 'hermeneutic' designs that help realise human potential.

These essays represent a more mature philosophy of technology, then, by avoiding the dystopianism, essentialism and technological determinism sometimes found in the tradition, and by their presentation of constructive reform proposals. Moreover, they tend to pay closer attention to technology itself: there is discussion of particular technologies such as computer technology (Winograd), media technologies (Ihde, Ezrahi) and medical technology (Longino), technological design (Winner, Winograd), and artefacts (Latour, Dumouchel). Classical positions (such as those of Heidegger and members of the Frankfurt School) are examined critically and confronted with empirical work in technology studies, and there is more of a tendency, generally, to supplement macro-level analyses with concrete examples and micro-level analyses that help substantiate them and give them more content (for example, Winner does not just present an abstract vision of a restructured public sphere in which citizens can more effectively influence technological choices, but draws on Scandinavian experiments in this direction to illustrate his views).

If these are positive transformations that the philosophy of technology is experiencing, it needs to be pointed out that many of these transformations are still far from complete. There is still room for change, particularly for more empirically informed philosophical studies. One would like to find more philosophical analyses of particular technologies (as found in Longino, Winograd, Ihde and Ezrahi). One would also like to find philosophical studies of the social and cultural changes wrought by technology that are more sensitive to the history of technology, and that are tied more strongly to the actual world we live in. Finally, one would like to find macro-level analyses of technologies and their consequences that are more seriously informed by micro-level analysis, and reform proposals that pay more attention to the internal structure of the institution of technology and the constraints that govern technological choice. 


\section{New Directions}

Close attention to specific technologies and to the history of technology, the employment of micro-level analyses of technological development, a consideration of the internal structure of the institution of technology and the constraints that govern technological development, these are all ingredients of the essays in New Directions. Yet, most essays in this anthology are not

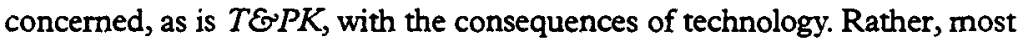
are limited to an analysis of the institution of technology by which technologies are developed and implemented. There are twelve essays in New Directions, concerned with a variety of issues grouped under one of four themes: the relation between technology and science, normative issues in applied science research and technological choice, the structure of technological revolutions, and cultural and philosophical implications of particular technologies. These essays will be discussed somewhat more extensively here, because of their radical departure from mainstream philosophy of technology.

Three essays are concerned with the relation between technology and science. Pitt puts forward the thesis that 'progress in science is a direct function of increasing sophistication not merely in instrumentation, but in the technological infrastructure that underlies and makes mature science possible' (p. 13). Pitt argues that a proper explanation of scientific change requires an analysis of the technological infrastructure of science and the way it interacts with scientific theory. Here, Pitt claims, lies a new and promising research program. DeNicola is also concerned with the relation between scientific theory and technology, although his interest is restricted to scientific instruments. He discusses the various functions that instrumentation plays in research, and argues that scientific instruments come to embody assumptions of the scientific paradigm in the context of which they have been designed. Kroes studies the influence of scientific knowledge on technological development, which he sees as part of the general problem of how science contributes to technology. He argues against the popular conception of technology as applied science and the linear, determinist model of technological development this brings with it, instead arguing that science plays the role of providing powerful heuristics for the solution of technological problems.

Five other essays address normative issues in applied science research and technological choice. Thompson argues that the most effective point of intervention for the direction of technological choice is at the stage of research choice, and proceeds to analyse the disciplinary structure of applied science. Research choice in applied science, he argues, is not just determined by the rewards system that is operative, but also by foundational 
technological values operating within applied science laboratories, such as productivity and efficiency. He argues that the technological, means-end character of these values corresponds with the means-end structure of research in applied science. This makes it difficult to change to new, more qualitative goals such as sustainability and distributive justice, because this would require a transformation of the fundamental structure of research itself. Thompson's essay is followed by a commentary by Heyboer and a reply by Thompson. Also following up on Thompson's essay, Shepard discusses the claims to autonomy of the applied sciences, particularly of agricultural science. Such claims to autonomy have historically been justified by the idea of technological neutrality. Shepard argues that this rests on the idea of the value neutrality of science, and proceeds to argue against this. Finally, Laymon discusses the role of idealisation in science, engineering, and normative theory, and presents an argument that the normative component of technological choice is affected by the way in which idealisation takes place.

Two essays consider the cultural and philosophical consequences of particular technologies. Wachtel considers the epistemological and cultural implications of the technology of transparent glass, as found in windows. Transparent glass windows, Wachtel argues, have fostered a conception of space and time as separate entities, with space conceptualised as empty cardboard floating along a constant current of time. Citing many historical sources, he aims to show how this conception of space and time has generated, in both art and science, the Western world view. Hahn considers the influence of monumental architecture on the origins of Western philosophy and science. Making extensive use of historical data, he argues that the conception of a geometrically modelled cosmos held by the early Greek philosopher Anaximander was strongly influenced by the structure of monumental architecture in his time. Hahn's essay is part of a larger project that aims to demonstrate that a proper understanding of Western rationality requires an understanding of the material culture in which it is embedded. The structure of technological revolutions is addressed by Cook, who argues against technological determinist models that centre around particular episodes of innovation, and in favour of a model in which the social changes brought about by technological revolutions are the result of multiple, mutually influencing technological and social innovations.

The essays in New Directions tend to adopt a narrow definition of technology, as science-based material technology. Most do not have as their main emphasis the (cultural, social and psychological) implications of technology but focus squarely on the institution of technology itself. Here, then, one finds a conception of philosophy of technology that resembles that of the philosophy of science. Even more so, many essays stand at the intersection of philosophy of science and philosophy of technology. Another recurrent 
feature is the great attention paid to history. There is little armchair philosophising here, and philosophical arguments tend to be backed up by references to studies in the history of science and technology. Most contributors are analytically trained philosophers of science, or else historians, and most references are also in the philosophy of science and in the history of science and technology. References to traditional philosophy of technology are conspicuously lacking, except for Pitt's claim that 'philosophers of technology are increasingly interested in more than arcane exercises in Heideggerian logic or in mere social criticism' (p.vii).

This volume, then, attempts to establish philosophy of technology as part of the analytic tradition. However, with so many sources derived from the philosophy of science and the history of science and technology, can these essays be categorised as philosophy of technology, rather than philosophy of science or history essays? Some essays, notably those by Wachtel, Hahn and Cook, might plausibly be argued to be cultural or intellectual history, or the history of technology, rather than philosophy. Many others might as easily be classified as philosophy of science as philosophy of technology. Pitt, for example, is clearly concerned with the explanation of scientific change, and analysis of technological infrastructure is a means to this end. Likewise, DeNicola's interest in the role of instruments in science is clearly conditioned by his interest in science rather than in instruments. The essays on applied science, finally, may be identified as philosophy of science at least as easily as philosophy of technology.

Defending these as essays in the philosophy of technology requires a liberal definition of philosophy of technology such as the one proposed earlier. Just as the philosophy of technology may overlap with social philosophy or philosophy of culture, it may overlap with philosophy of science, or even with history. Thus, the relation between science and technology is an issue for both the philosophy of science and the philosophy of technology. Still, one may have expected more essays in which the main interest is technology itself. For example, as Pitt observes, this anthology does not include essays in philosophy of engineering. It would have been interesting to see what philosophical issues a consideration of engineering and engineering design would evoke.

In his introduction to New Directions, Pitt claims that these essays reflect a philosophy of technology that is ready to enter the philosophical mainstream. Pitt here clearly refers to mainstream analytic philosophy. There are two ways a discipline can become part of the establishment. One is to demonstrate its intrinsic importance; the other is to demonstrate its instrumental value to other disciplines. What many of the essays demonstrate is the importance of the study of technology for other disciplines, such as the philosophy of science, metaphysics, and ancient philosophy. Only a few, such 
as the essays by Kroes and Cook and arguably the essays on applied science, demonstrate the intrinsic appeal of an 'analytic' philosophy of technology. One would want to see more such examples to be convinced of the possibility of a coherent program of research in 'analytic' philosophy of technology.

In the mean time, this anthology shows that there are important issues at the intersection of philosophy of technology and philosophy of science, and at the intersection of philosophy of technology and history. These issues should provide room for a collaboration between philosophers of technology, philosophers of science, and historians of science and technology and cultural historians. Moreover, I would want to suggest that some of the work here may prove to be highly relevant to mainstream philosophy of technology. The more detailed analyses of the dynamics of technological change and the possibilities for directing technological choice may provide important correctives for some of the theses put forward in mainstream philosophy of technology (for example, theses concerning the 'autonomy' of technology), and may also help to assess and direct some of its proposals for an 'alternative' technology.

\section{Philosophy and Technology}

Philosophy and Technology, edited by Roger Fellows, presents a range of topics still more diverse than those found in TEPK and New Directions. The essays derive from a Royal Institute of Philosophy conference on Philosophy and Technology, held in the United Kingdom. This is one of very few British publications on this theme; unlike the United States and many European countries, Great Britain has no history of research in the philosophy of technology. Most contributors to this volume are philosophers who have been publishing in mainstream (mostly analytic) philosophy. They are to be commended for their effort to reflect on the topic of technology. Yet, it is somewhat startling that the essays neglect virtually all previous work in the philosophy of technology. Indeed, readers could walk away from this volume thinking that it represents one of the first efforts of philosophers to study technology.

Some of the twelve essays are not seriously concerned with technology or its consequences. These include an essay by Bambrough on style in philosophy, and essays by Hendry and Cartwright in the philosophy of science, both concerned with scientific realism, with no reference to technology. Two other essays which read like essays in the philosophy of science, at least consider the role of technology. Thus, Smithurst considers whether successful technologies confirm the truth of scientific theories, and Hackmann considers the role of scientific instruments in natural science. 
These essays clearly fall within the scope of an 'analytic' philosophy of technology as featured in New Directions.

There are also essays that reflect broadly on technology and its social and cultural consequences. Cooper asks whether technology a force for liberation or enslavement, and argues that technological societies have eroded the notion of the self. Clark argues that technology cannot bring us complete control of our environment, and opts that instead we should conceive of technological artefacts as wonderful marvels that we cannot even fully control. Grant outlines an instrumentalist conception of technology according to which the essence of technology is the furtherance of ends through neutral means. However, he warns against technocracies, because ends tend to be corrupted in them. O'Hear considers the effect of new technologies on art and argues that art created or reproduced with the aid of computers cannot qualify as art because it lacks the element of craft. Gyekye, finally, presents an interesting philosophical-anthropological-historical analysis of the reason why no scientific and technological revolutions occurred in Africa and explores the consequences of his analysis for technology transfer policies.

Although some interesting novel analyses of technologies and their consequences are proposed, most essays are likely to disappoint those already familiar with work in philosophy of technology. This is especially so for essays that broadly reflect on technology and its consequences without consideration of any previous work in the philosophy of technology. These tend to say little that is new, or, worse, hold positions that have long been discredited. For example, the instrumentalist conception of technology outlined by Grant, according to which technology is a neutral tool for the furtherance of desired ends, is considered an ancient relic by most philosophers of technology. Yet, Grant treats this conception as a discovery and uses it to dismiss (unidentified) critics of technology, who, he argues, must either be confused or have some sort of hidden agenda. In general, many essays in this volume could have benefited from closer attention to already existing work in the philosophy of technology.

\section{Conclusion}

An answer to the question of whether the philosophy of technology has the characteristics of a mature discipline may be: yes and no. Yes, because technology has been shown to raise a number of important philosophical questions, which have lead to a cumulative exchange of views. Yes, because much recent philosophy of technology meets philosophical standards of rigour. No, because philosophy of technology is still a fragmented field; there are few issues or approaches that most or all philosophers of technology share. 
No, because the infrastructure and visibility of the field remain weak, indicated by the fact that there are no regularly appearing journals in philosophy of technology, few philosophy programs in which serious attention is paid to philosophy of technology, and little knowledge by mainstream philosophers of work in philosophy of technology.

The philosophy of technology seems to be gaining in coherence and importance, however. Philosophical questions concerning technology are becoming important in areas such as environmental ethics, feminist philosophy, and postmodernist philosophy. As these areas gain in importance and move into mainstream philosophy, it is becoming easier for the philosophy of technology to establish itself as part of mainstream philosophy. Moreover, as both TEOPK and New Directions show, philosophers of technology have come to share interests with those working in science and technology studies, notably with sociologists and historians of technology. Here is an area of possible interaction and interdisciplinary work that is already fruitfully being explored. These developments may stimulate the further maturation of the philosophy of technology and an increased prominence in the academic scene.

Department of Philosophy, Twente University, Enschede, The Netherlands.

1. Of those falling most clearly within the scope of philosophy of technology, other than the three anthologies reviewed here, one might mention the following: Carl Mitcham, Thinking Through Technology: The Path Between Engineering and Philosophy, Chicago: University of Chicago Press, 1994; Andrew Feenberg, Alternative Modernity:The Technical Tum in Philosophy and Social Theory, Berkeley: University of California Press, 1995; Lorenzo C. Simpson, Technology, Time, and the Conversations of Modernity, London: Routledge, 1995; Raphael Sassower, Cultural Collisions: Postmodern Technoscience, London: Routledge, 1995; David Strong, Crazy Mountains: Learning from Wilderness to Weigh Technology, Albany: SUNY Press, 1995; Mary Tiles and Hans Oberdiek, Living in a Technological Culture: Human Tools and Human Values, London: Routledge, 1995; Frederick Ferré (ed.), Technology and Everyday Life: Research in Philosophy and Technology vol. 14, Greenwich, Conn.: JAI Press, 1994; Carl Mitcham (ed.), Social and Philosophical Constructions of Technology, Research in Philosophy and Technology vol. 15. Greenwich, Conn: JAI Press, 1994; Richard Coyne, Designing Information Technology in the Postmodern Age: From Method to Metaphor, Cambridge, MA: MIT Press, 1995; Alan Drengson, The Practice of Technology: Exploring Technology, Ecophilosophy, and Spiritual Disciplines for Vital Links, Albany: SUNY Press, 1995; William Lovitt \& Harriet Lovitt, Modern Technology in the Heideggerian Perspective, vol. I \& vol. II, Lewiston: Mellen Press, 1994 \& 1995. 
Beyond these works, one can find many multi- or interdisciplinary works and works in feminism, history, social theory and cultural studies that also address philosophical issues concerning technology, such as: Richard E. Sclove, Democracy and Technology, New York: Guilford Press, 1995; Aronowitz et al. (eds), Technoscience and Cyberculture:A Cultural Study, London: Routledge, 1995;David Channell (ed.), The Relationship Between Science and Technology:An Anthology of Historical and Philosophical Articles from Technology and Culture. Chicago: University of Chicago Press, 1995; Merritt Roe Smith and Leo Marx (eds), Does Technology Drive History? The Dilemma of Technological Determinism, Cambridge, MA: MIT Press, 1994; Johan van der Pot, Stezuard or Sorcerer's Apprentice? The Evaluation of Technical Progress:A Systematic Overview of Theories and Opinions vol. 1 \& 2, Delft, Netherlands: Eburon, 1994; Richard Buchanan and Victor Margolin (eds), Discovering Design, Chicago: University of Chicago Press, 1995.

2. The following works may be mentioned: Friedrich Rapp, Analytical Philosophy of Technology, Boston: Reidel, 1981; Ernest Byrne and Joseph Pitt, Technological Transformation: Contextual and Conceptual Implications (Philosophy and Technology vol. 5), Dordrecht: Kluwer 1989; Peter Kroes and Martijn Bakker (eds), Technological Development and Science in the Industrial Age (Boston Studies in the Philosophy of Science vol. 144), Dordrecht: Kluwer, 1992; Rachel Laudan (ed.), The Nature of Technological Knowledge: Are Models of Scientific Change Relevant, Boston: Reidel, 1984; Jon Elster, Explaining Technical Change: $A$ Case Study in the Philosophy of Science, Cambridge: Cambridge University Press, 1983. New Directions should also be included in this list.

3. Paul Durbin, 'Conflict over Philosophy of Technology as an Academic Field,' Broad and Narrow Interpretations of Philosophy of Technology (Philosophy and Technology vol. 7), ed. by Paul Durbin, Dordrecht: Kluwer, 1990. For a more extensive review of the history of philosophy of technology, see Don Ihde, Philosophy of Technology: An Introduction, New York: Paragon House, 1993, and Carl Mitcham, op. cit. 